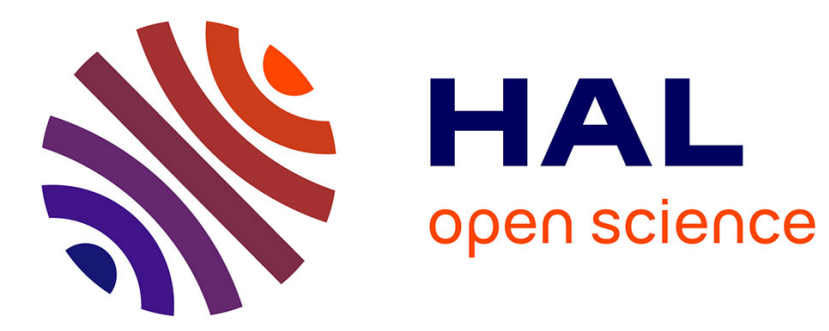

\title{
Recommendations for Autonomous Industrial Vehicle Performance Standards
}

Roger Bostelman

\section{To cite this version:}

Roger Bostelman. Recommendations for Autonomous Industrial Vehicle Performance Standards. Roger Bostelman, Elena Messina, "Autonomous Industrial Vehicles: From the Laboratory to the Factory Floor", STP1594, Chapter 8, May 2016., 2016. hal-01401486

\section{HAL Id: hal-01401486 https://hal.science/hal-01401486}

Submitted on 23 Nov 2016

HAL is a multi-disciplinary open access archive for the deposit and dissemination of scientific research documents, whether they are published or not. The documents may come from teaching and research institutions in France or abroad, or from public or private research centers.
L'archive ouverte pluridisciplinaire HAL, est destinée au dépôt et à la diffusion de documents scientifiques de niveau recherche, publiés ou non, émanant des établissements d'enseignement et de recherche français ou étrangers, des laboratoires publics ou privés. 


\title{
Recommendations for Autonomous Industrial Vehicle Performance Standards
}

\author{
Roger Bostelman \\ Intelligent Systems Division \\ National Institute of Standards and Technology \\ Gaithersburg, MD 20899-8230, USA \\ roger.bostelman@nist.gov \\ IEM, Le2i, Université de Bourgogne, \\ BP 47870, 21078 Dijon, France
}

\begin{abstract}
A workshop was held at the IEEE International Conference on Robotics and Automation, called: "Autonomous Industrial Vehicles: From the Laboratory to the Factory Floor". Nine research papers were presented followed by a discussion session summarized in this paper. The workshop findings are intended to be useful for developing standards within the ASTM F45 Committee for Driverless Automatic Industrial Vehicles. This paper provides feedback from the discussion listing the example organizations in attendance at the workshop and suggests recommendations for standards that evolved from the discussion.
\end{abstract}

\section{Introduction}

A workshop entitled "Autonomous Industrial Vehicles: From the Laboratory to the Factory Floor" was held as part of thelnternational Electrical and Electronics Engineering (IEEE) Robotics and Automation Society's flagship International Conference on Robotics and Automation (ICRA) [1] on May 30, 2015 at the Washington State Convention Center in Seattle, Washington, USA. The annual conference is a premier international forum for robotics researchers to present their work. The workshop drew over 60 attendees and participants from many organizations and countries around the world, including:

\begin{tabular}{|l|l|}
\hline \multicolumn{1}{|c|}{ organization } & \multicolumn{1}{c|}{ country } \\
\hline Adept Technology Robotics & USA \\
\hline Amazon & USA \\
\hline ASTM International & USA \\
\hline Boeing & USA \\
\hline Brain Corporation & USA \\
\hline Clearpath Robotics & Canada \\
\hline Crown Equipment & New Zealand \\
\hline Elettric 80 Inc. & USA \\
\hline Johns Hopkins University & USA \\
\hline Kirinson - Hokuyo Automatic Co., Ltd. & USA \\
\hline Microsoft & USA \\
\hline Mujin & Japan \\
\hline National Institute of Standards and Technology & USA \\
\hline Orebro University & Sweden \\
\hline RWTH Aachen University & Germany \\
\hline ShanghaiTech University & China \\
\hline Sick & Germany \\
\hline University of Modena and Reggio Emilia & Italy \\
\hline
\end{tabular}




\begin{tabular}{|l|l|}
\hline University of Massachusetts - Lowell & USA \\
\hline University of Zagreb & Croatia \\
\hline Vecna Technologies & USA \\
\hline
\end{tabular}

The purpose of the workshop was to solicit researcher input for the development of consensus standards within ASTM International Committee F45 on Driverless Automatic Industrial Vehicles [2], and to inform researchers towards a standard-based mechanism for rapid technology transfer from the laboratory to industry. Additionally, the National Institute of Standards and Technology (NIST) hosted the event for research basis for two projects within the Smart Manufacturing Robotics Program: Robotic Systems for Smart Manufacturing project and Performance of Collaborative Robot Systems project.

Some industry driving questions for workshop presenters and attendees to consider prior to the event were:

- what various lighting, dust, and floor conditions are evident in industry?;

- what associated vehicle speeds, tolerances, and equipment access conditions are required?;

- what communications speeds, integration issues, and control strategies are useful on today's typically-closed industrial AGV controllers versus tomorrow's, potentially more open controllers?

- what minimal mobile robot knowledge of its environments is required, but can perhaps adapt to it versus current AGVs that only have path information, navigation knowledge, and less intelligence?

- what onboard or interactive equipment for AGVs should be considered, such as robots that access AGVs or are onboard AGVs as advanced mobile manipulation systems?

The response from research paper solicitation included topics most closely related to: ASTM F45 background and status, obstacle detection and avoidance, navigation, planning, ground truth measurement in support of AGV test method development, mobile robot and AGV capabilities, and movement of industrial vehicle technological innovations from inception to commercial use. As such, many of the above pre-questions listed were embedded in presentations and post-presentation discussions.

This paper initially discusses the ASTM F45 Committee. Next, the paper discusses previous standards recommendations for ASTM F45, highlights the post-presentation discussions from the ICRA Workshop, and providesupdated recommendations towards standards developments within ASTM F45. Included, from the final Workshop discussion session, are summarized notes collected and formalized into direct F45 committee and subcommittee standards development information.

\section{ASTM F45 Committee}

In general, ASTM F45 includes performance test methods and terminology for autonomous industrial vehicles. The committee was formed to dovetail with current AGV safety standards, such as American National Standards Institute/Industrial Truck Safety Development Foundation (ANSI/ITSDF) B56.5:2012, Safety Standard for Driverless, Automatic Guided Industrial Vehicles and Automated Functions of Manned Industrial Vehicles. [3] The F45 scope is as follows:

The development of standardized nomenclature and definitions of terms, recommended practices, guides, test methods, specifications, and performance standards for driverless automatic guided industrial vehicles. The Committee will encourage research in this field and sponsor symposia, workshops, and publications to facilitate the development of such standards. The work of this Committee will be coordinated with other ASTM technical committees and other national and international organizations having mutual or related interests.

The thrust of this effort is towards industrial vehicles. However, autonomous mobile robot developments applied to other industries have advanced vehicle technology and can also provide advancements to the manufacturing vehicle industry. Therefore, test method developments that may provide advancements to other than industrial vehicles should also be considered. 


\section{Chapter 8}

Book: "Autonomous Industrial Vehicles: From the Laboratory to the Factory Floor", STP1594, May 2016

ASTM F45 structure is as follows:

- Subcommittee F45.01 on Environmental Effects

- Subcommittee F45.02 on Docking \& Navigation

- Subcommittee F45.03 on Object Detection \& Protection

- Subcommittee F45.04 on Communication \& Integration

- Subcommittee F45.91 on Terminology

\section{Previous Standards Recommendations}

To date, three initial working documents have been submitted to the ASTM F45 and are being developed by task groups with regards to navigation, docking, and terminology. Recommendations within the navigation document for subcommittee ASTM F45.02 are test methods for both computer aided design (CAD) model point-to-point, line segment, navigation (path following) as well as, simultaneous localization and mapping (SLAM) navigation (corridor traversal). Figure 1 shows an example of a confined area layout for a navigation test method. CAD model commanded navigation is more traditional for AGV's whereas SLAM is more recently implemented in some AGV's and mainly used in mobile robots. The standard working document allows for various vehicle sizes and capabilities, as depicted in Figure 1 showing example AGV sizes and course lengths for the various vehicle sizes. The blue line depicts the traditional AGV path following while the red lines depict moveable walls to allow SLAM navigation within reconfigurable corridors.

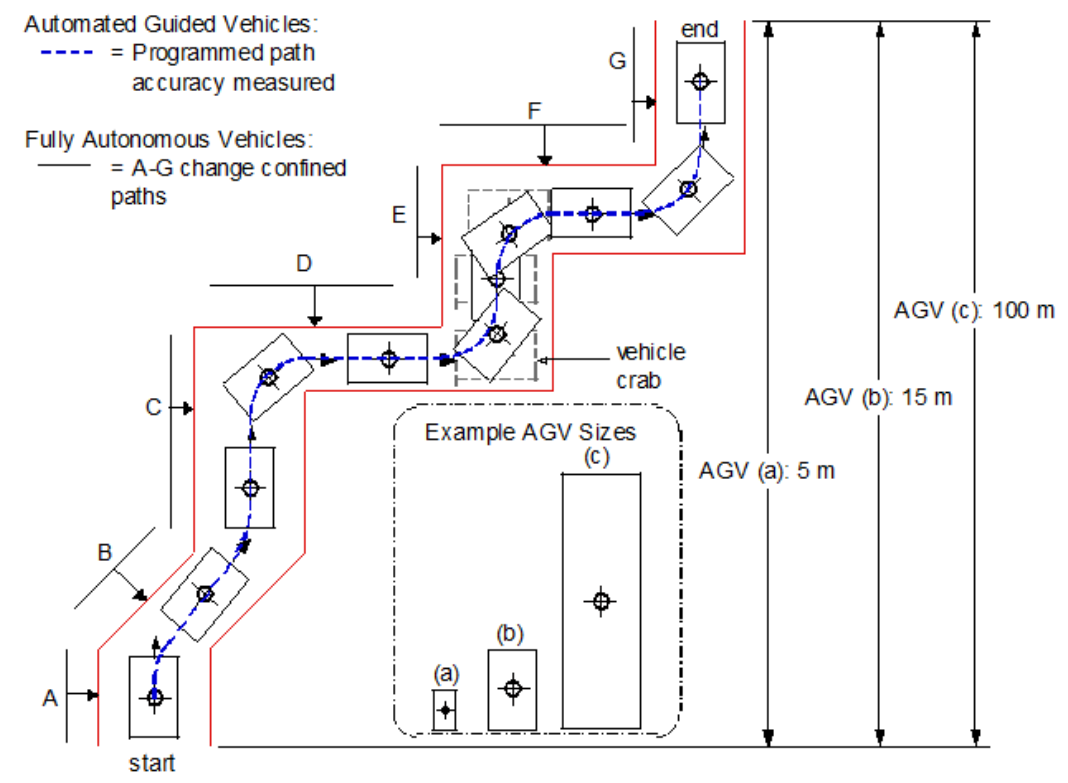

Figure 1 - Example autonomous industrial vehicle confined area navigation test method setup as shown in ASTM F45.02 navigation working document.

Alternatively, open space autonomous industrial vehicle navigation is also described as a test method in ASTM F45.02 navigation working document. Open space tests are described as being simple geometric shaped paths (square, circle, straight line) for the vehicle to navigate.

ASTM F45.02 has also started a working document on docking industrial vehicles with the environment. Again, as with navigation, various size vehicles are exemplified within the document as shown in Figure 2. 


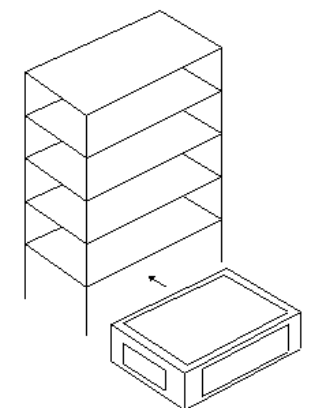

a

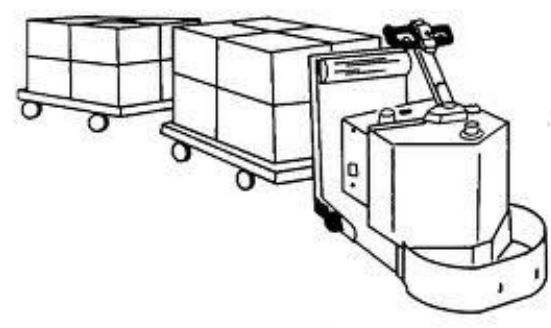

b

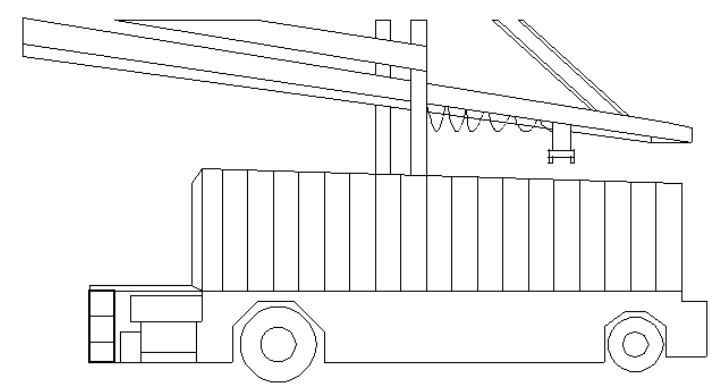

c (b)

(a)

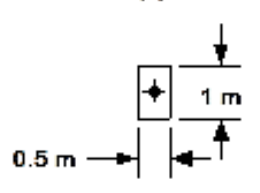

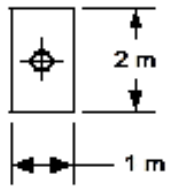

$\mathrm{d}$ (c)

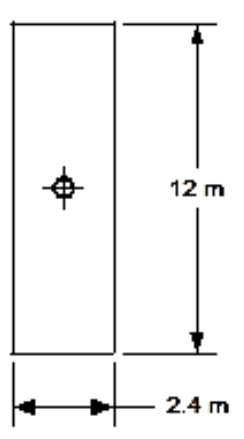

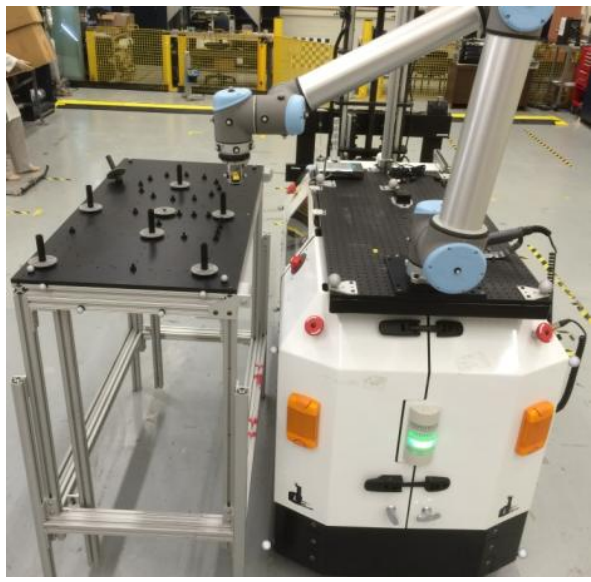

$\mathrm{e}$

Figure 2 - Top view of example AGV size variability: (a) low-profile, (b) industrial tug, (c) container AGV. (Image b courtesy www.mhi.org) (d) Vehicle size variability examples.(e) NIST mobile manipulator being used for performance test method development for assembly tasks.

Figure 2 (a) and (c) show unit load vehicles of various sizes and Figure 2 (b) shows a tugger vehicle. Not shown is a forklift vehicle. Figure 2 (d) shows example vehicle size variability and Figure 2 (e) showsthe NIST mobile manipulator being used for performance test method development for assembly tasks. All of the vehicles require docking with varying types of precision, where the NIST mobile manipulator requires much less docking uncertainty than a typical unit load or tugger vehicle. One conceptfor generic docking, shown in Figure 3 , is to command the vehicle to access a point (a) followed by a second point (b) or to contact both point (a) and point (b) simultaneously. 


\section{Chapter 8}

Book: "Autonomous Industrial Vehicles: From the Laboratory to the Factory Floor", STP1594, May 2016

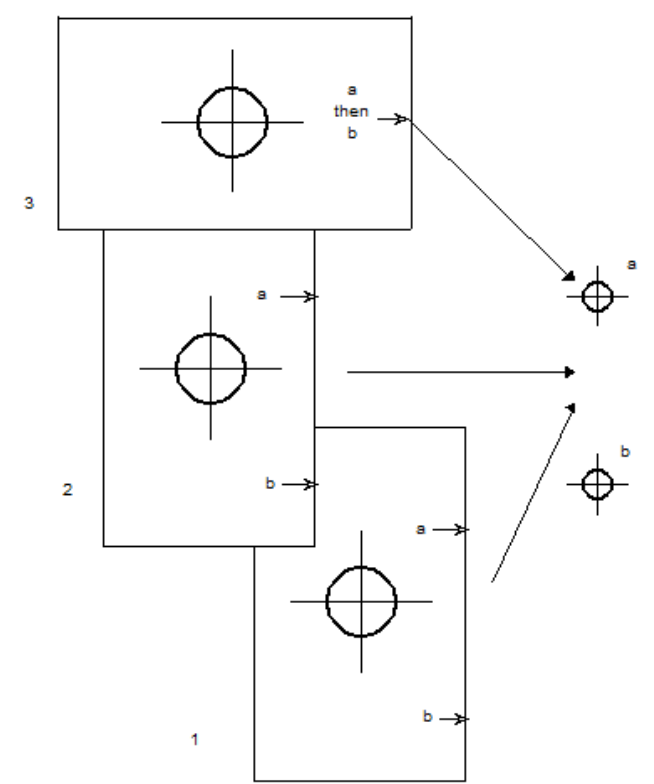

Fig. 3 - Example vehicle (left) and apparatus dock points (a) and (b) (right) for docking tests using various AGVs. Points "a" and " $b$ " are fixed points in space (e.g., contact or non-contact sensor locations in space). Approach vectors and sensor point spacing and locations are variable.

ASTM F45.02 has also received further recommendations towards standards developments for docking and navigation. Specifically, threequestions were documented and distributed to the committee to foster discussion towards supporting current or developing new working documents:

1. How accurately does the AGV stop at dock/assembly mating locations?

- pallets (low or high pick/place) - least accuracy needed

- tray stations, ISO lock insertion - more accuracy needed

- OR for insertion of pegs (sheet goods, long rods, etc.) into assemblies - high accuracy needed

- OR to pick-up/place delicate equipment - high accuracy needed

2. How accurately does the AGV navigate?

- $\quad$ straight or curved paths

- Ackerman, all-wheel, or crab/quad steering

- what is the tightest turning radius at various speeds

- when programmed to make the tight turn, does it actually accomplish it or navigate a different curve?

- $\quad$ Between error-correct markers (e.g., inertial, magnets, RFID, etc.)

- Between obstacles, racks, other infrastructure

3. What does it do when it senses a human vs. another obstacle?

The ASTM F45.91 subcommittee task group has started working on a terminology document to define typically used terms of the AGV and mobile robot industries. Initial document development began with terms defined by three organizations: ANSI/ITSDF, Material Handling Industry of America [4], and International Standards Organization (ISO) ISO/FDIS 8373:2011 [5].

Additional questions and parameters were also distributed for input and comment from F45.01, F45.03, and F45.04 subcommittees to foster standard test method developments, including:

\section{F45.01 Environmental Effects}

1. How fast and capable is the vehicle to navigate in the following environments?:

- Indoor 


\section{Chapter 8}

Book: "Autonomous Industrial Vehicles: From the Laboratory to the Factory Floor", STP1594, May 2016

- Temperature (freezer)

- Lighting (none/sunlight)

- Humidity (none/wet)

- Dust/Dirt

- Outdoor

- Temperature (e.g., extreme heat/cold)

- Lighting (day/night)

- Humidity/precipitation (dry/rain, snow)

- Fog, smoke

- Dust/Dirt

- Surfaces

- Smooth/rough terrain

- Floor gaps

- Surface Slope

- Level

- Slope angle - $>0^{\circ}$

- Areas

- Confined
○ Walls
- Obstacles (safety guards, rails, columns, etc.)
- Other agents

- Open

- Entrance and exit to/from areas
- Softwall curtain partitions
- Automated doors
- Open doorway spaces

- Interaction with other agents

- Humans working on the line

- Humans operating other machinery

- Humans operating/programming the AGV

- Other AGVs performing similar tasks

2. What procedure is required to implement the AGV into an environment with the characteristics outlined above?

- Map of the space

- Manually program/provide map to the AGV

- Drive AGV around the space to build its own map

- Augment space with path following/boundary edge markers

- Modifications to task space (activities aside from navigation)

\section{F45.03 Object Detection \& Protection}

1. How well does the AGV react to situations?

- Obstacles appearing in the path

- Potential obstacles headed towards the path

- Unstructured areas not on the original planned path or that rapidly change

2. (.02?) How far off the commanded navigation path can an AGV be, and at what speeds, before it violates the path and causes a stop? Examples:

- Offset-pitched/rolled AGV can't see reflectors, magnets, wire, etc.

- Tape is worn or broken

- Terrain causes "bouncing" or moving laser or other nav sensors

3. Human detection

- $\quad$ Represented by test pieces, mannequins, humans 


\section{Chapter 8}

Book: "Autonomous Industrial Vehicles: From the Laboratory to the Factory Floor", STP1594, May 2016

- $\quad$ Coverings (e.g., clothes worn)

4. Interaction with manual operations (e.g., forklifts, machines)

5. Intelligence

- Autonomy level ${ }^{1}$

- $\quad$ Situation awareness

For instance (using LASSO):

- Location (where it is within a global map; orientation with respect to landmarks)

- Activites (what activities it is performing or should be; progress towards completing its task/mission)

- $\quad$ Surroundings (what obstacles are nearby, what type of terrain it is on, local information)

- $\quad$ Status (battery health, damaged sensor, askew camera, current mode)

- Overall mission (total progress towards completing a task/mission involving all agents; i.e., for these purposes the entire manufacturing floor or a particular group working on the same overall task)

\section{F45.04 Communication \& Integration}

1. What is the Comm integrity?

- How well does the vehicle function with intermittent or complete comm loss?

2. Systems integration

- Addition of equipment, sensors, algorithms

- Autonomous/manually reconfigurable

- $\quad$ Assistance: Sensors (e.g., RFID) or specific factory clothes worn by workers

- Given the type of AGV power system, such as AC or DC, low-V or high-V, lead-acid/sealed-lead acid batteries/hydrogen fuel cell, etc. and given payload, daily-use, system longevity, environmental effects:

- mean time between failures/maintenance (MTBF/M)?

- mean time between battery charge?

- Synchronization among vehicles

- Wait to pick up load

- Not cause congestion

- Reliability - fewer faults

- Reduced dependence on operators

- Maintenance: Diagnostics, Changes, Repairs

\section{Recommendations Towards Standards}

A discussion was held during the closing session of the 2015 ICRA "Autonomous Industrial Vehicles: From the Laboratory to the Factory Floor"Workshop. The discussion session allowed an open forum of workshop presenters and attendees to discuss their views on developing standards within ASTM F45 for AGVs and mobile robots. The response was impressive with much participant interaction. The workshop hosts captured responses in bulleted form and displayed the written responses on screen during the discussion for audience viewing. The responses were as follows:

- Representative facility components

- How closely related to the components is needed?

- Test piece coatings that represent worst case

- Physical relationships between components relevant to the application, task, system, components

- Performance vs. safety test methods

\footnotetext{
${ }^{1}$ For example: Sheridan model scale (slide 27): http://www.nist.gov/el/isd/ks/upload/ALFUS-BG.pdf
} 


\section{Chapter 8}

Book: "Autonomous Industrial Vehicles: From the Laboratory to the Factory Floor", STP1594, May 2016

- If safety standards don't include test methods, perhaps performance test methods should be standardized for the 'safety' situations

- Performance standards should 'dovetail' with safety standards

- $\quad$ Obstacle detection/avoidance - two modes:

- 'Stop' or 'drive around obstacles'

- Multiple vehicles - 2 vs 10 vs 100 - how to test multiple vehicles when manufacturers and users don't have so many vehicles

- Standards for virtual modeling of vehicles so that the test does not require many vehicles

- Dynamic routing

- Vehicle-to-vehicle (local) versus vehicle-to-central (broad) controller communication

- Understand the environment - environments that remain the same (floor, dust, light, infrastructure, communication, etc.) versus environments that change

- Autonomy/learning - how to measure?

- Over long and short periods of time

- Need standard basis for perception systems performance

- Mapping accuracy, repeatability of created maps

- Mean time to failure - e.g., communication between vehicles and controllers

- Communication interference measurement

- 'heartbeat' communication from central controller/monitor versus no need for continuous communication (e.g., intelligent vehicles)

- Test methods should not be based on the vehicle system and instead allow developers to use whatever design they choose

- Networking should be standardized for connections to vehicles so that all robot systems installed in facilities can communicate regardless of the network or robot manufacturer

- Central versus decentralized control performance comparison

- Measure communication - level of autonomy dependent

- For example, a remote switch for safety - how reliable is it?

- Navigation with and without markers

- Don't over-specify how vehicles navigate - should it be metric based? i.e., is it absolute accuracy-based?

- Standards for communications interfaces to robots, vehicles, facility sensors

- Building integration standard - should there be a working group in this area?

- Similar to elevators, fire doors

- Standards that allow robots to adapt to the facility, including communicating with any of the facility components

- $\quad$ Standard data sets of facilities - warehouses, hospitals, etc. used to allow manufacturers to develop and test their vehicle systems prior to integration into facilities

- Standard benchmarks and standard testbed to support this industry

- Integration of multiple-vendor components and robots

o There is not one vehicle, robot system and therefore need to demonstrate integration from multiple manufacturers

- Eliminate friction to adoption of autonomous vehicles by providing open source

- Develop generalized test methods to test the relevant part or activity of the system so that the component, system, etc. performance can be measured as compared to the task

- Can't test every possible combination of the system as compared to a task, therefore generalize the test method to capture most important aspect

- ASTM E54.08.01 [6] and other standards can be used as a good model for vehicle performance standards development.

The workshop presentations and closing discussion provided several areas that have not been previously considered towards standards developments. The enthusiasm of the workshop presenters and attendees 


\section{Chapter 8}

Book: "Autonomous Industrial Vehicles: From the Laboratory to the Factory Floor", STP1594, May 2016

demonstrated an obvious need for developing new industrial vehicle performance standards, as well as the components (e.g., communication/network, virtual test data sets, testbed facilities, etc.) that support these systems.

\section{Acknowledgements}

The authors would like to thank the IEEE International Conference on Robotics and Automation "Autonomous Industrial Vehicles: From the Laboratory to the Factory Floor" Workshop attendees and participants. Their feedback and support for the workshop provided necessary standard development focus. As well, the authors would like to thank Sebti Foufou, University of Qatar, for his editorial guidance.

\section{Summary and Conclusions}

NIST and ASTM initiated a workshop called "Autonomous Industrial Vehicles: From the Laboratory to the Factory Floor". The workshop was designed to promote autonomous vehicle developments and highlight implementations that have occurred and thosethat are on the horizon as examples for workshop attendees to consider for standards development within the ASTM F45 Committee. Three working documents towards potential near-term F45 standards are currently being developed. A post-presentations discussion session was then held and allowed workshop attendees to provide input for new F45 and other standards document developments. This enthusiastic session provided continuous flow of brainstorming ideas that, in summary can be listed as supporting the following key points that directly mimic ASTM F45 subcommittee thrusts, minus terminology:

- Environmental Effects

- Docking \& Navigation

- Object Detection \& Protection

- Communication \& Integration

Other key areas were in standardized building infrastructure protocols, networking, testbeds and other important standards development areas. Future efforts will utilize this workshop summary to develop new standard performance test methods for autonomous industrial vehicles.

\section{References}

1. International Electrical and Electronics Engineering (IEEE) International Conference on Robotics and Automation http://icra2015.org/, 2015

2. ASTM International, ASTM F45 Committee for Driverless Automatic Industrial Vehicles, www.astm.org/Standards/F45, 2015.

3. ANSI/ITSDF B56.5:2012,Safety Standard for Driverless, Automatic Guided Industrial Vehicles and Automated Functions of Manned Industrial Vehicles, http://www.itsdf.org, Nov 2012.

4. Material Handling Industry of America, Automatic Guided Vehicle Systems, http://www.mhi.org/glossary, 2014.

5. ISO/FDIS 8373:2011(E/F) Robots and robotic devices - Vocabulary, 2014.

6. ASTM International, ASTM E54.08.01Robots for Urban Search and Rescue. Performance Metrics and Standards, http://www.astm.org/Standards/E54.08.01, 2015 